\title{
La producció de l'espai en la modernitat líquida
}

\author{
Josep Pueyo-Ros
}

Universitat de Girona. Departament de Geografia

jospueyo@gmail.com

\section{Resum}

L'article vol mostrar que el marc teòric de la modernitat líquida, definit per Zygmunt Bauman, pot oferir perspectives i camps d'exploració nous en l'estudi dels fenòmens geogràfics. La divisió de l'espai en tres parts (pràctiques espacials, representació de l'espai i espais de representació), ideada pel sociòleg francès Henri Lefebvre, serà el punt de partida. Per a cada dimensió espacial, s'hi analitza un exemple utilitzant la modernitat líquida com a marc d'anàlisi. Aquests exemples són, successivament: les polítiques de desenvolupament local, la geoweb i els no-llocs com a nous espais simbòlics. Al final de l'article, s'hi valoren les aportacions de la modernitat líquida a l'anàlisi de cadascun dels tres exemples, així com algunes aportacions possibles que el marc de la modernitat líquida podria oferir a l'anàlisi geogràfica.

Paraules clau: anàlisi geogràfica; modernitat líquida; desenvolupament local; geoweb; no-llocs.

\section{Resumen. La producción del espacio en la modernidad líquida}

El artículo quiere mostrar que el marco teórico de la modernidad líquida, definido por Zygmunt Bauman, puede ofrecer nuevos campos de exploración y nuevas perspectivas en el estudio de los fenómenos geográficos. La división del espacio en tres partes (prácticas espaciales, representación del espacio y espacios de representación), ideada por el sociólogo francés Henri Lefebvre, será el punto de partida. Para cada dimensión espacial, se analiza un ejemplo utilizando la modernidad líquida como marco de análisis. Dichos ejemplos son, sucesivamente: las políticas de desarrollo local, la geoweb y los no-lugares como nuevos espacios simbólicos. Al final del artículo, se valoran las aportaciones de la modernidad líquida al análisis de cada uno de los ejemplos, así como algunas posibles aportaciones que el marco de la modernidad líquida podría ofrecer al análisis geográfico.

Palabras clave: análisis geográfico; modernidad líquida; desarrollo local; geoweb; no-lugares. 
Résumé. La production de l'espace dans la modernité liquide

L'article veut nous démontrer que le cadre théorique de la modernité liquide, défini par Zygmunt Bauman, peut nous offrir de nouveaux champs d'exploration et de nouvelles perspectives en ce qui concerne l'étude des phénomènes géographiques. Le point de départ est la division de l'espace faite par le sociologue français Henri Lefebvre entre : les pratiques spatiales, la représentation de l'espace et les espaces de représentation. Pour chaque dimension spatiale on analyse un exemple en utilisant la modernité liquide comme cadre d'analyse; ceux-ci sont, successivement: les politiques de développement locales, la géoweb et les non-lieux comme nouveaux espaces symboliques. Á la fin de l'article il y a une évaluation des apportations que peut faire la modernité liquide dans chacun des trois exemples et certaines apportations possibles que le cadre de la modernité liquide pourrait offrir à l'analyse géographique.

Mots-clés: analyse géographique; modernité liquide; développement local; géoweb; non-lieux.

\section{Abstract. The production of space in liquid modernity}

The article aims to show how the theoretical framework of liquid modernity, explained by Zygmunt Bauman, can offer new fields for exploration and new perspectives on the study of geographical phenomena. The article is based on the division of space conceived by French sociologist Henri Lefebvre in spatial practice, representation of space and representational spaces. An example in each dimension is analyzed using liquid modernity as an analytical framework; these are, successively: local development policies, geoweb and no-places as new symbolic spaces. At the end, the article acknowledges the value of contributions from liquid modernity to analyze each example, and also some possible contributions that liquid modernity could offer for a geographical analysis.

Keywords: geographical analysis; liquid modernity; local development; geoweb; no-places.

\section{Sumari}

1. Introducció 4. Els no-llocs, els nous espais simbòlics

2. El desenvolupament local com a pràctica espacial líquida de la modernitat líquida

3. Geoweb: cartografies líquides per representar l'espai

5. Conclusions

6. Agraïments

Referències bibliogràfiques

\section{Introducció}

La societat de les últimes dècades ha estat analitzada per molts autors i batejada amb molts noms diferents. Sens dubte, el més conegut d'aquests termes és postmodernitat, que agafa volada amb el llibre del filòsof i sociòleg francès Jean Francois Lyotard (1979): La condition postmoderne: rapport sur le savoir. Tot i que postmodernitat continua essent un terme molt utilitzat per referir-se a la societat del capitalisme postfordista, han sorgit molts més termes que han anat matisant i afinant el concepte. Alguns exemples destacats són societat del 
risc, encunyat per Ulrich Beck (1992), o societat xarxa, definit per Manuel Castells (2000).

En les discussions sobre la societat postfordista, existeixen dos grans grups. D'una banda, un que considera que la societat actual es troba immersa en una modernitat tardana, és a dir, en una nova etapa de la modernitat. En aquest grup, s'hi troben pensadors com ara Scott Lash, Ulrich Beck, Anthony Giddens o el propi Bauman, entre altres (Cools, 2010: 88). Aquest grup està en contraposició amb els pensadors postmoderns, que defineixen la postmodernitat com una reacció contra tot allò que és modern.

Zygmunt Bauman, després d'estudiar a fons la modernitat i la postmodernitat, l'any 2000 concep també el seu propi terme per descriure l'etapa postfordista: la modernitat líquida (Bauman, 2003a). Una de les motivacions de Bauman per encunyar aquest nou concepte és la d'eliminar ambigüitats respecte a la seva posició en el debat sobre la postmodernitat, ja que sovint havia estat etiquetat com a sociòleg postmodern (Arenas, 2011). La terminologia de Bauman ha estat ben acollida en el món acadèmic, sobretot en la filosofia i la sociologia, fins al punt que els diferents conceptes s'han constituït en el que Piñon (2013) anomena "quasicosmovisions» de la societat occidental de finals del segle xx i principis del xxI. Però el concepte de modernitat líquida no només s'ha fet un lloc en les ciències socials, sinó que també té el mèrit d'haver aconseguit traspassar la barrera del món acadèmic fins que ha esdevingut una de les metàfores preferides de la nostra societat per intentar comprendre, de manera reflexiva, el moment que ens ha tocat viure (Arenas, 2011). Sánchez (2006) engloba els termes de Bauman dins les metàfores d' «allò líquid», un tipus de metàfores que l'autor considera que han adquirit una importància especial en el «turbulent corrent social dels nostres dies»" ${ }^{1}$, i que s'utilitzen per parlar d'una societat on tot flueix.

Bauman, com molts altres autors que escriuen sobre la postmodernitat, forma part del que s'ha anomenat "gir espacial» de les ciències socials. Una de les crítiques que rep aquest gir espacial és que s'ha obviat el treball que alguns geògrafs feia anys que duien a terme per tal d'incorporar l'espai al cos de la teoria social (Puente, 2011). Malgrat les crítiques, no es pot obviar que l'anàlisi espacial és determinant en la modernitat líquida, atès que, tal com argumenta Bauman (2003a: 8), la característica principal de l'era líquida és que el temps guanya importància en relació amb l'espai, ja que aquest perd el valor estratègic que tenia en la modernitat sòlida (l'època del capitalisme fordista), pel fet que desplaçar-se ja no costa temps, que és la variable significativa, tot i que uns altres autors, com ara Soja (Benach et al., 2010), presenten arguments contraris, perquè veuen la postmodernitat com una oportunitat perquè l'espai recuperi el protagonisme que havia perdut en l'època fordista. En tot cas, el que és segur del tot és que la modernitat líquida, així com la postmodernitat, representa un canvi en la relació entre l'espai i el temps. Però Bauman concreta la seva anàlisi sobre l'espai i reflexiona també sobre els territoris de la modernitat

1. Traducció de l'autor. 
líquida. Bauman explica que els territoris han deixat de tenir el paper d'àrbitre entre el capital i el treball i han passat a ser un jugador més en la lluita per atraure inversions i llocs de treball, de manera que el capital i el poder es tornen extraterritorials i, amb la promesa d'instal-lar-se en un territori o altre, poden extorsionar els polítics locals, que romanen lligats al territori. Bauman, en la seva definició de la modernitat líquida, toca també molts més aspectes relacionats amb l'espai: parla d'identitat i comunitats, de nacionalismes, de les ciutats, de la mobilitat, etc., conceptes que són clarament de l'interès de la geografia.

Malgrat tot, les teories de Bauman no han aconseguit fer-se un lloc en el món de la geografia. Segons informacions de la base de dades Scopus ${ }^{2}$, de les 1.205 citacions que acumula Liquid Modernity, només 15 corresponen a revistes de l'àmbit de la geografia, i cap d'aquests articles té la modernitat líquida com a mot clau, sinó que es limiten a utilitzar el marc teòric de la modernitat líquida per reforçar els arguments exposats, tal com fan Igoe et al. (2010) en el seu article sobre conservació i neoliberalisme o Quaglieri i Russo (2010) quan parlen de turisme i d'hipermobilitat. Altres autors utilitzen idees secundàries del llibre, on Bauman parla sobre la delinqüència (Ferrell, 2012), les transformacions urbanes (García i Bujalance, 2011) o la mobilitat (Halfacree, 2012), entre d'altres.

Que no hi hagi articles de geografia que versin sobre la modernitat líquida no significa que la geografia no s'hagi preocupat d'estudiar els canvis que ha viscut la societat des de la caiguda del règim fordista, sinó que aquesta s'ha decantat per utilitzar el terme postmodernitat, analitzat des de la geografia amb certa rellevància per David Harvey (1998) i Edward Soja (1990). Però la modernitat líquida de Bauman difereix en alguns punts amb la postmodernitat de Harvey i Soja. Per aquest motiu, una anàlisi geogràfica utilitzant el marc teòric dibuixat per Bauman pot complementar el coneixement que la geografia ha anat acumulant en la seva anàlisi sobre la societat del capitalisme tardà.

Així doncs, el propòsit d'aquest article és realitzar una anàlisi geogràfica utilitzant el marc teòric que ofereix la modernitat líquida, amb l'objectiu de demostrar que aquesta pot oferir camps nous d'exploració i perspectives noves en l'estudi dels fenòmens geogràfics. Per fer-ho, s'utilitzaran tres exemples, cadascun dels quals se situen en una de les tres dimensions de l'espai formulades per Henri Lefebvre (1991), sociòleg, geògraf i filòsof francès de tendències marxistes, tot i que considerat dins el marxisme un autor controvertit $\mathrm{i}$ heterodox. Lefebvre va realitzar nombrosos estudis sobre l'espai, especialment sobre l'espai urbà. Les seves obres més influents en l'àmbit de la geografia són, probablement, Du rural à l'urbain, de 1971, i La production de l'espace, de 1974, en aquesta última serà on desenvoluparà les tres dimensions esmentades. Aquestes tres dimensions són:

1. Les pràctiques espacials, que inclouen la producció de l'espai físic, les pràctiques materials i les polítiques espacials.

2. Cerca realitzada el 2 d'abril de 2013. 
2. La representació de l'espai, on l'objectiu és entendre com la forma de representar l'espai afecta la seva producció.

3. Els espais de representació, que són projectes utòpics -imaginats o construïts-simbòlics per a la societat, que imaginen sentits nous o possibilitats noves en les pràctiques espacials.

Escollir aquesta classificació per estructurar l'anàlisi es fonamenta en un cert consens entre els geògrafs crítics que consideren que utilitzar una classificació que diferenciï entre l'espai real i el metaforic evita el risc de caure en idealismes. D'altra banda, privar l'espai d'aquestes tres dimensions seria privar-lo del seu potencial crític (Puente, 2011). Un altre motiu per utilitzar la classificació de Lefebvre és el fet que els dos geògrafs principals dedicats a l'estudi de la postmodernitat, Harvey i Soja, també l'utilitzin. Harvey (1998) se serveix de la classificació de Lefebvre, tot i que ho fa de forma bastant tímida i controvertida; mentre que Soja (1996), per part seva, ho desenvoluparà definitivament al llibre Thirdspace i el posarà en pràctica a Postmetropolis: Critical studies of cities and regions (Soja, 2000). Cal aclarir, però, que aquestes categories s'utilitzen només com a punt de partida a l'hora d'escollir els exemples que s'analitzaran. L'article no pretén reflexionar a l'entorn dels conceptes de Lefebvre ni mirar com encaixen en les idees de Bauman. Tot i això, Harvey i Soja fan diferents interpretacions de la classificació de Lefebvre. Aquest article es mostra més proper a la interpretació que fa Harvey per a cadascuna de les dimensions.

Per a l'article en concret, en la dimensió de les pràctiques espacials, s'hi analitzen les polítiques de desenvolupament local i com aquestes, en el marc de la modernitat líquida, provoquen banalització i superficialitat en els territoris i els paisatges. Com a exemple de representació de l'espai, s'hi analitza la geoweb com a nou paradigma de la ciència cartogràfica, nascuda en sintonia amb la societat moderna líquida. I, en tercer lloc, dins la categoria d'espais de representació, s'hi valora com aquells espais que en la modernitat sòlida es consideraven no-llocs (Nogué i Albet, 2007) esdevenen llocs simbòlics en l'era líquida.

\section{El desenvolupament local com a pràctica espacial líquida}

Cada moment de la història humana ha generat els espais necessaris per posar en marxa la maquinària del sistema social, polític i econòmic. D'exemples, se'n troben molts, des de l'àgora fins als parlaments actuals, des dels feus de l'època medieval fins a les fabriques fordistes. La societat moderna líquida no n'és l'excepció i també produeix els espais que calen perquè pugui funcionar. Alguns són necessaris per al funcionament de l'economia global, com ara terminals informàtiques, llocs de recepció i d'intercanvi d'informació, etc. (Muñoz, 2008: 45). Uns altres espais neixen fruit de les necessitats d'una nova societat que requereix espais nous per a funcions noves. Un exemple el trobem en la gran proliferació d'espais dedicats al lloguer de trasters, necessaris per a la vida nòmada de la modernitat líquida, on la hipermobilitat s'ha convertit en l'estil de vida de les elits (Bauman, 2003a: 19). Un altre espai produït per la 
modernitat líquida són les oficines compartides, on treballadors individuals, que només necessiten un ordinador portàtil per dur a la pràctica la seva professió, poden llogar una taula i sentir-se envoltats d'altres persones que, igual que ells, també han optat per una feina en el món en línia i que, a les oficines compartides, poden trobar quelcom similar a companys de feina. Hi ha molts altres exemples d'espais produïts per les necessitats d'una vida líquida, però, en general, Muñoz (2008: 66) considera que els nous espais han de complir dues condicions: ser divertits i segurs, amb la qual cosa es plasmen dues característiques molt importants de la modernitat líquida: la cerca del plaer immediat i la priorització de la seguretat (Bauman, 2003a: 149).

Però la modernitat líquida no és un estat final, sinó un procés, una etapa d'interregnum, en què el món antic és mort, però el món nou encara no ha nascut (Bauman, 2012), per la qual cosa, més que analitzar uns espais que han perdut la solidesa que tenien en altres èpoques, és segurament més útil analitzar els processos que produeixen aquests espais, és a dir, les polítiques espacials. En aquest sentit, el marc de la modernitat líquida pot ajudar a entendre per què, durant l'última dècada, el desenvolupament local ha anat guanyant protagonisme respecte a unes altres polítiques de caire més centralitzat, no només des d'un punt de vista teòric, sinó també a nivell operatiu i en la pràctica (Dematteis i Governa, 2005).

Com ja s'ha dit, la modernitat líquida és una societat on cal canviar constantment per romandre sempre allà mateix. Per descriure-ho, Bauman (2006: 9) utilitza la metàfora de córrer sobre el gel, és a dir, la seguretat la dóna la velocitat. I quan el canvi és la norma, la incertesa és permanent. En aquest context, la planificació centralitzada perd sentit, perquè els plans només poden ser de curt termini (Bauman, 2003a: 147), raó per la qual el desenvolupament local es presenta com l'alternativa més adequada davant la incertesa. Però el desenvolupament local no només ha aparegut com a "pla B» a la crisi de la planificació, sinó que també presenta algunes característiques que permeten qualificar-lo de política espacial líquida.

Consumir és un fet eminentment individual. No es necessita ningú més per anar a comprar, a més a més, consum i individualisme es necessiten i s'alimenten, ja que l'exigència de la individualització és el motor del consum (Bauman, 2006: 38), al contrari de produir, que és un acte fruit de la col-lectivitat. Així doncs, mentre que la societat de la modernitat sòlida era una societat de productors, la societat moderna líquida és una societat de consumidors, on tots els nostres actes emulen el fet d'anar a comprar. Una societat on tot es basa a ser consumit instantàniament, fins i tot la mà d'obra o les relacions interpersonals, amb la garantia que, si no es queda satisfet, es pugui substituir (Bauman, 2003a: 174). Per tant, la societat moderna líquida, com a societat basada en el consum, és una societat individualista. Això condueix a buscar solucions individuals a problemes col-lectius, amb la qual cosa es generen fracassos que també són individuals. Aquest individualisme es tradueix, a nivell territorial, en el desenvolupament local, on s'empeny cada territori a trobar solucions als seus problemes. Uns problemes que, sovint, tenen solucions globals, però que 
el desenvolupament local intenta solucionar des de l'escala local, amb màximes de l'estil «Pensa localment i actua localment» (sic) (Abad, 2010), amb la qual cosa es cau en una visió «localista» intrínseca al desenvolupament local (Dematteis i Governa, 2005).

D'altra banda, en la societat moderna líquida actual, la salut ha estat substituïda per l'estar en forma, que és un camí constantment inacabat, ja que sempre es pot estar més en forma (Bauman, 2006: 126). Aquesta filosofia també s'aplica als territoris, de tal manera que les teories del desenvolupament local els obliguen a estar en forma, és a dir, a millorar constantment. Traduït a les polítiques territorials, aquest estar en forma significa territoris innovadors, intel-ligents, emprenedors, creatius, etc. (Méndez et al., 2006), adjectius que impliquen renovació constant. I aquesta millora contínua es presenta com a obligatòria, perquè tots els llocs aspiren a convertir-se en el destí d'una planta industrial, d'un centre comercial o d'un turista (Nogué i Albet, 2007: 161) i aquests sempre trien els territoris en forma. Però sense una intervenció centralitzada, cada territori és responsable de la sort que pugui tenir, la qual cosa els empeny a competir entre ells, perquè triomfar o no en l'aparador global només depèn dels esforços i de les habilitats de cadascú.

En aquesta competició entre territoris, les polítiques urbanes busquen atraure capital amb actuacions orientades a un mercat transnacional (Muñoz, 2008: 55). Un capital que, en la modernitat líquida, ha esdevingut extraterritorial $i$, tot i que molt sovint s'ha de sotmetre als governs locals, sense una intervenció coordinada, o centralitzada, pot extorsionar aquests poders, gràcies, precisament, a la seva mobilitat (Bauman, 2003a: 159). Un exemple paradigmàtic el trobem en la manera com Sheldon Adelson instava Barcelona i Madrid a competir entre elles per aconseguir la instal-lació de l'Eurovegas, amb la qual cosa els obligava a oferir-li avantatges fiscals, canvis legislatius, excepcions urbanístiques, etc. De manera que el capital es converteix en la metàfora del client que va a comprar, escollint entre territoris exposats en un aparador global. Però aquest, immers en la dinàmica líquida, no pot aturar-se a mirar el contingut del que compra, només té temps de fixar-se en la imatge. Per aquest motiu, la construcció de marca ha passat a tenir un paper molt important en les polítiques de desenvolupament local, de manera que ha obligat les ciutats a cuidar més que mai la seva imatge superficial (Harvey, 1998: 112), amb la qual cosa s'han convertit elles mateixes en un luxós embolcall (García i Bujalance, 2011). Així, mentre que la ciutat de la modernitat sòlida restava indiferent a la seva imatge exterior, prioritzant el control de les funcions internes, la ciutat moderna líquida té el seu capital més valuós en la imatge i l'atracció (Nogué i Albet, 2007: 191). I si només compta la imatge, els paisatges poden ser copiats d'un lloc a l'altre, perquè han perdut l'obligació de representar el lloc (Muñoz, 2008: 51).

Aquesta repetició de paisatges també s'explica per la teoria del sinòptic de Mathiesen (1997), que Bauman (2003a: 92) descriu com una de les característiques de la modernitat líquida. En el sinòptic, la majoria vigila una minoria seleccionada, que, a nivell espacial, es tradueix en el fet que uns territoris 
intentin imitar uns altres territoris que s'han convertit en referents. D'aquesta manera, cadascun vol esdevenir part d'aquesta minoria seleccionada per poder atraure capital. En aquest nou paradigma sinòptic, la competència entre els llocs acaba generant una monotonia recursiva i serial a partir de pautes conegudes, de manera que es van produint llocs idèntics (Boyer, 1988; citat a Bauman, 2003a: 327). En aquest sentit, trobem exemples com ara Getafe, $\mathrm{amb}$ una important indústria aeronàutica, que es planteja, en la seva política de desenvolupament local, construir una Airbus Ville imitant Toulousse, que és el lloc de referència en matèria d'indústria aeronàutica (Méndez et al., 2006).

Els processos de banalització de llocs i paisatges sempre s'han analitzat partint d'un punt de vista $u p$-bottom, ja sigui des dels processos de globalització (Romero i Ortega, 2007) o partint dels canvis en el règim d'acumulació capitalista (Harvey, 1998), però el marc de la modernitat líquida permet, partint de la individualitat, donar la volta als processos de banalització sobre els quals tant s'ha escrit. En aquest capítol, s'ha pogut comprovar com les actituds individualistes de la societat moderna líquida condicionen les pràctiques espacials afavorint polítiques també individualistes, com ara el desenvolupament local. És interessant observar que tant si la trajectòria de l'anàlisi és up-bottom com si és bottom-up, s'arriba al mateix destí: la producció arreu d'uns espais banalitzats i repetits que no tenen cap més funció que fer d'embolcall a l'aparador global. Això és degut a la circumstància que els processos de banalització són més complexos del que fins ara s'intuïa. Aquests impliquen múltiples escales, raó per la qual cal realitzar una anàlisi que relacioni l'escala local, baixant fins a nivell de l'individu, amb la global, per estudiar com s'encavalquen totes dues en la producció de l'espai.

\section{Geoweb: cartografies líquides per representar l'espai}

La representació que una societat fa de l'espai és igual d'important per a la producció de l'espai que les pròpies pràctiques espacials, perquè aquestes representacions sovint poden esdevenir fins i tot espais simbòlics per a la societat que les ha creades (Hallin i Dobers, 2012). Caquard (2013) explica que els mapes, que són l'eina més estesa de representació de l'espai, expliquen històries que, alhora, reflecteixen i també creen realitat. D'altra banda, Hallin i Dobers (2012) expliquen que aquestes representacions no són mai objectives. Argumenten que llegir l'espai utilitzant el treball d'un altre (la producció de mapes) significa que la percepció de l'espai està condicionada a la visió de qui l'ha plasmat. És, doncs, un espai mediat. Per tant, el tipus de mapa, i l'origen d'aquest, pot canviar la percepció de l'espai de qui l'utilitza (Phipps, 2011).

Quan Lefebvre, l'any 1974, va escriure La production de l'espace, el fet d'elaborar mapes i representar l'espai estava en mans de la ciència i dels professionals. Actualment, amb el que s'ha anomenat "geoweb» o "neogeografia»"

3. És més recomanable utilitzar el concepte geoweb per evitar confusions amb la neogeography, nascuda als anys setanta amb la revolució quantitativa de les ciències socials. 
— amb Google Maps com a plataforma hegemònica-, la representació de l'espai és en mans de tothom (Haklay et al., 2008). Així doncs, els mapes estàtics són substituïts per una nova generació de mapes digitals que provoquen que les representacions que omplen el lebenswelt en la modernitat líquida siguin virtuals i no físiques (Bauman, 2003b).

Per esquematitzar les diferències principals d'aquest canvi de paradigma, es pot traçar un joc de parelles dicotòmiques entre els mapes de la modernitat sòlida i els mapes digitals de la modernitat líquida:

\begin{tabular}{cl}
\hline Cartografia sòlida & Cartografia líquida \\
\hline Col·lectius & Individuals \\
Públics & Privats \\
Territorials & De navegació \\
\hline
\end{tabular}

A la primera de les parelles, hi apareix la dicotomia entre el que és col-lectiu i el que és individual, una de les parelles que defineixen més bé les diferències entre la societat de productors de la modernitat sòlida i la societat de consumidors. Amb la cartografia, aquest joc també existeix, mentre que, a la modernitat sòlida, elaborar cartografia era una feina costosa, que necessitava un treball col-lectiu per poder ser realitzada, atès que calien cartògrafs, impressors, editors, etc. Amb la geoweb, qualsevol persona amb els coneixements necessaris i un ordinador portàtil pot utilitzar l'API de Google Maps i elaborar els seus propis mapes (Batty et al., 2010), tot i que la geoweb permet produir mapes de manera individual, alhora que també ofereix la possibilitat de realitzar un treball col-lectiu compartit, gràcies a les TIC, en una dimensió abans impensable. El més rellevant, però, és que, mentre que, a l'era moderna, elaborar cartografia era una tasca exclusivament col-lectiva, la geoweb obre les portes a la producció individual. Un aspecte important que es deriva d'aquest canvi, plasmat a la segona parella dicotòmica, és que mentre que, abans, la cartografia era una tasca eminentment pública, principalment a mans dels estats, a la modernitat líquida es converteix en una tasca privada, on fins i tot les bases cartogràfiques són elaborades per actors privats com ara Google o Microsoft. Apareix, així, un altre dels processos característics del pas de la modernitat sòlida a la líquida: la privatització de l'esfera pública.

L'última parella dicotòmica versa sobre la funció dels mapes. En la modernitat sòlida, la tasca principal d'un estat era exercir la sobirania territorial (Bauman, 2003a: 122), per tant, la funció principal de la cartografia havia de ser el control del territori i de les persones que hi vivien. Però, en la modernitat líquida, el territori ha perdut importància, la funció principal d'un estat ja no és exercir la sobirania territorial - funció que, malgrat tot, continua essent rellevant-, sinó atraure capital transnacional (Bauman, 2003a: 196). Per aquest motiu, els mapes han esdevingut plataformes de navegació, que ja no intenten ser el màxim de fidels possible a la realitat, sinó el màxim de fun- 
cionals possible (Caquard, 2013). La cartografia s'ha adaptat a la vida nòmada líquida que necessita mapes actualitzats de manera constant per fer front al canvi i a la incertesa de la vida líquida, perquè l'antiga lluita entre grans i petits és ara entre ràpids i lents (Bauman, 2003a: 198).

Fins ara, s'ha vist com la producció de mapes a la societat del capitalisme tardà guarda una estreta relació amb el marc teòric de Bauman. Però és en el consum d'aquests mapes on la relació amb la modernitat líquida és més directa i els servidors de mapes digitals — també dits remescles — es poden considerar mapes fets a mida per a la societat moderna líquida. En primer lloc, mentre que, a la modernitat sòlida, el cartògraf centrava el mapa allà on creia convenient, les remescles estan centrades en un mateix, atès que posen l'usuari o consumidor al centre del mapa, perquè, en la societat moderna líquida, el més important és l'individu, és a dir, un mateix. D'altra banda, les remescles permeten al consumidor decidir quina és la informació que el mapa ha de mostrar, a més, ofereixen informació personalitzada de manera automàtica en funció de la informació que el servidor té de l'usuari, amb la qual cosa esdevé un símil perfecte d'anar a comprar, que se sustenta en la llibertat d'escollir entre opcions infinites i la personalització, una metàfora perfecta de la vida líquida (Bauman, 2003a: 68).

Bauman (2010) utilitza sovint el concepte de xarxa com a metàfora de la societat moderna líquida, on tot és concebut com un entramat, des de les relacions interpersonals fins a l'economia global. La cartografia digital encaixa perfectament en aquest marc, perquè les remescles estan formades per nodes units per línies, de manera que dibuixen una xarxa on el tot es transforma en parts d'un tot (Caquard, 2013). Recuperant una afirmació anterior, si les representacions de l'espai modifiquen la nostra percepció dels llocs, es pot afirmar, doncs, que les remescles afavoreixen la percepció de l'espai com a xarxa, amb la qual cosa complementen a la perfecció la metàfora enunciada per Bauman. Concebre el territori com una xarxa no és una qüestió poc transcendent. Santos (1995) elabora una crítica de la visió del territori com a xarxa, que considera que està guanyant pes en les disciplines territorials. Santos denuncia que les xarxes uneixen verticalment, amb la qual cosa deixa abandonat el que anomena «espai trivial», que és l'espai intersticial de la xarxa. En el món de les remescles, on es poden visualitzar zones de tot el planeta, els espais trivials són aquells que no tenen rellevància, que no surten als buscadors de Google Maps. En aquesta mateixa línia, Graham i Zook (2011) afirmen que la visibilitat d'un espai físic depèn de la seva visibilitat a Internet, que és el principal aparador global de la modernitat líquida.

Relacionar la geoweb amb la modernitat líquida dóna un nou enfocament a l'estudi de la primera. És important observar com, sense tenir una relació aparent, els dos conceptes encaixen a la perfecció, de manera que l'un reforça l'altre. Mentre la geoweb fa possible la vida líquida, oferint mapes a l'altura de les exigències d'aquesta, la societat moderna líquida ofereix el marc perquè la cartografia digital deixi de ser d'interès només per a les disciplines espacials i esdevingui una eina d'ús generalitzada per a totes aquelles persones que 
busquen adaptar-se a l'estil de vida líquid. D'aquesta estreta relació, en surt afectada la percepció de l'espai, condicionada pel nou paradigma en la cartografia, que ens permet familiaritzar-nos amb la globalitat de l'era líquida visitant virtualment espais de qualsevol racó del planeta, una forma de viatjar en sintonia la vida líquida, on el contingut és el preu que es paga per poder desplaçar-se sense esforç.

\section{Els no-llocs, els nous espais simbòlics de la modernitat líquida}

S'ha mostrat com la cartografia digital pot modificar la percepció de l'espai, però la geoweb no és l'única responsable d'aquest canvi de percepció. L'estil de vida líquid, nòmada i basat en la velocitat, modifica també la percepció de l'espai, fins al punt que obliga a replantejar el simbolisme que tenen l'espai i els llocs per a les societats dels capitalisme potsfordista.

Els espais simbòlics són, segons Monnet (2011), aquells espais tangibles que connecten la societat amb quelcom intangible. En aquest sentit, es pot considerar que tots els espais són simbòlics, ja que cada espai geogràfic té una dimensió tangible i intangible (Pries, 2005). Però, evidentment, alguns espais compleixen millor que d'altres la seva funció simbòlica. En aquest sentit, Monnet considera que els símbols més comuns són els espais desenvolupats per les administracions públiques, perquè són entesos i compartits per tothom.

En la diversa bibliografia que ha publicat, Bauman defineix quatre arquetips de persona: turista, rodamón, caminant i jugador (Bauman, 1996). Per als espais simbòlics, és important considerar els arquetips del turista i el rodamón, ja que són els que estan relacionats més directament amb l'ús de l'espai (Bright, 2010: 92). El turista representa les elits de la modernitat líquida; el rodamón, al contrari, simbolitza les persones que viuen al marge de la modernitat líquida. Tant el turista com el rodamón són sinònims de mobilitat, però, mentre el primer es mou perquè troba el món irresistiblement atractiu, el rodamón es desplaça perquè el troba insuportablement inhòspit. La forma de moure's d'uns $i$ altres també presenta diferències importants. El turista es trasllada segons un pla, segons uns propòsits. El rodamón, d'altra banda, decideix cap a on ha de girar quan arriba a cada intersecció. Pel que fa a la identitat, el problema del turista és escollir-ne una entre les moltes disponibles i no aferrar-s'hi gaire per quan toqui canviar-la. El rodamón, en canvi, representa aquelles persones que continuen aferrades, de forma reactiva i tribal, a una única identitat, que l'apedaçaran tant com puguin abans de veure's obligats a desprendre-se'n, i això, precisament, és el que els obliga a desplaçar-se: la falta de llocs on puguin fermar aquesta identitat. Segons Bauman, la societat moderna líquida es debat entre aquestes dues postures (Bauman, 2006: 15).

És d'esperar, doncs, que els espais simbòlics de la modernitat líquida també es debatin entre aquestes dues postures. Aquest debat l'exemplifica molt bé Castells (1995) amb la lluita del que ell anomena «l'espai de fluxos» contra «l'espai dels llocs». Mentre el primer seria l'espai simbòlic dels turistes, els rodamons continuen aferrats a l'espai dels llocs, sobretot a aquells llocs que 
havien estat simbòlics en l'etapa sòlida de la modernitat, com ara les ruïnes i les antiguitats, que els ofereixen un punt d'ancoratge en un món que es transforma ràpidament (Harvey, 1998: 301). Per als turistes, en canvi, els espais simbòlics són els que representen mobilitat, els que fan possible l'espai de fluxos i que, per tant, el representen simbòlicament (Monnet, 2011).

Considerar la maquinària sinòptica de la modernitat líquida (Bauman, 2003a: 92) porta a la conclusió que els espais simbòlics de les elits són els que esdevenen comuns per a tota la societat, uns espais dels quals es potencia el simbolisme mitjançant la publicitat que se'n fa (González-Romero, 2010), una de les eines més importants del sinòptic. És per aquest motiu que Castells (1995: 485) considera que l'espai de fluxos ha dominat l'espai dels llocs. En aquesta línia, Bauman (2003b) considera que, per a la societat moderna líquida, «l'espai simbolitza la continuïtat d'un viatge contínuament inacabat. En el transgressiu imaginari de la modernitat líquida, el lloc (físic o social) ha estat reemplaçat per una infinita seqüència de començaments nous» ${ }^{4}$. En aquest escenari emergent, esdevenen simbòlics aquells espais que són nodes de trànsit i de circulació, com ara els aeroports, o espais destinats a la velocitat, com ara les línies del tren d'alta velocitat; aquells espais que, en definitiva, no aconsegueixen associar-se a cap cultura territorial i que, en l'era sòlida, eren considerats no-llocs (Nogué i Albet, 2007: 175). No és casualitat, doncs, que Muñoz (2008: 43) cregui que l'aparició dels no-llocs va de la mà del desenvolupament de l'espai de fluxos. Aquests espais, on el protagonisme el tenen els fluxos de persones i mercaderies i no les construccions físiques, són l'expressió dels processos que dominen la vida econòmica, política i simbòlica de la societat postfordista (Albrechts i Coppens, 2003). Els no-llocs són importants perquè constitueixen nodes en una societat on la xarxa és l'estructura primordial, ja que són els encarregats de connectar els llocs amb la xarxa global, fent-los visibles en el mapa. Els nodes, doncs, utilitzant els termes de Castells, connecten els llocs amb l'espai de fluxos.

Per aquest motiu, Blatter (2004) considera que l'espai de fluxos ha substituït el territori per la seva funció, perquè elements territorials que en la modernitat sòlida eren simbòlics, com ara les muntanyes (Nogué i Vicente, 2004) o els gratacels (Monnet, 2011), han deixat de ser-ne en la modernitat líquida per deixar lloc a aquells espais la funció dels quals és la mobilitat, és a dir, mantenir en funcionament l'espai de fluxos.

Però, en la modernitat sòlida, el tren també es podia considerar un espai simbòlic, atès que representava el progrés i el triomf de la indústria. El simbolisme d'aquest es plasmava en les estacions, que esdevenien autèntics edificis monumentals símbol del poder. Les vies, d'altra banda, responien a criteris estrictament funcionals. A l'era líquida, en canvi, l'espai simbòlic és tant l'estació com el recorregut en si, que es plasma sobretot en els criteris de construcció d'aquest recorregut, com ara els ponts per on el tren creua una carretera, que ja no responen a normes estrictament funcionals, sinó que estan dissenyats per

4. Traducció de l'autor. 
esdevenir símbols de la velocitat, una característica primordial per triomfar en la modernitat líquida (Bauman, 2003a: 198).

Així doncs, mentre els espais simbòlics de la modernitat sòlida eren aquells que representaven fermesa i perdurabilitat, on la població s'hi podia aferrar per trobar una identitat que li duraria tota la vida. En la modernitat líquida, on el territori ha estat substituït per la xarxa i la perdurabilitat és percebuda com un llast del qual cal desprendre's, els espais que esdevenen simbòlics són precisament aquells que es mantenen al marge del territori, aquells espais que són llocs de pas on res és fix, sinó que tot flueix. En la línia de l’objectiu de l'article, en aquesta secció, s'ha pogut comprovar com el fet d'utilitzar el marc teòric de la modernitat líquida per analitzar els espais simbòlics ofereix un nexe entre la teoria dels no-llocs i l'espai de fluxos de Castells en relació amb el seu simbolisme, la qual cosa dóna un nou sentit als primers. D'altra banda, els arquetips de Bauman i la cerca d'identitat d'aquests en l'espai ofereix un nou enfocament al simbolisme de l'espai, que, òbviament, necessita un aprofundiment més ampli del que s'ha pogut realitzar en aquest article.

\section{Conclusions}

L'objectiu d'aquest article és mostrar que el marc teòric ofert per la modernitat líquida és capaç d'aportar noves perspectives i nous enfocaments a l'anàlisi geogràfica de l'espai. En el transcurs de l'article, s'ha fet evident que aquestes aportacions poden ser diverses. En el primer apartat, s'hi ha vist com la modernitat líquida ajuda a complementar les explicacions sobre l'èxit i la proliferació de les polítiques de desenvolupament local, així com les mancances que ofereix; s'hi ha vist també com el marc teòric de Bauman ofereix l'oportunitat d'analitzar les polítiques espacials partint de l'individu, en comptes de fer-ho des de l'escala macro, la qual cosa evidencia, alhora, la necessitat de realitzar una anàlisi transescalar que relacioni des de l'escala global fins a la dels individus, per poder entendre la complexitat de les polítiques espacials. D'altra banda, la geoweb, analitzada dins el context de la societat moderna líquida, s'ha mostrat com una eina indispensable per a les necessitats de la vida líquida, això explica l'explosió que ha viscut en els darrers anys, que han fet que sobrepassés l'àmbit d'interès de les disciplines espacials per esdevenir d'ús generalitzat. També s'ha pogut veure com aquesta nova cartografia reforça la percepció de l'espai com a xarxa, un espai xarxa que, a més, es mostra accessible i personalitzat a gust del consumidor. Finalment, en l'últim apartat, s'ha constatat com la modernitat líquida ofereix un nexe entre la teoria dels no-llocs i l'espai de fluxos en relació amb el simbolisme de l'espai, la qual cosa atorga un nou sentit als primers $\mathrm{i}$ ajuda a explicar el domini de l'espai de fluxos sobre l'espai dels llocs.

Així doncs, la modernitat líquida té molt a dir en la disciplina geogràfica, no només en l'àmbit teòric, sinó també en el pràctic, perquè la finalitat última de qualsevol estudi relacionat amb l'espai o el paisatge ha de ser la de millorar la qualitat de vida de les persones que hi viuen. I, per tant, cap estudi pot obviar el context social. La modernitat va arrencar l'home (i la dona) de la terra i els 
va obligar a realitzar el treball alienat; la modernitat líquida els ha arrencat del territori i els ha obligat a conviure en dos mons simultanis, el món en línia i el món fora de línia. En aquest sentit, el marc teòric de la modernitat líquida pot ajudar les disciplines territorials, centrades històricament en el món fora de línia, a endinsar-se també en l'estudi dels espais virtuals i imaginaris, avui tan importants com els materials. Tot i això, cal no oblidar, com molt bé conclou Puente (2011), «el que una vegada i una altra els materialistes de tota mena ens segueixen recordant encertadament, per, d'aquesta manera, no caure en els coneguts excessos postestructuralistes».

Malgrat que les teories de Bauman poden aportar un punt de vista nou a l'anàlisi geogràfica, cal dir també que no solucionen algunes de les simplificacions a les quals s'enfronta qualsevol interpretació simbòlica de la societat postmoderna, ja que aquestes tendeixen a simplificar en excés els trets de la societat actual i generen contraposicions que, en la realitat, sovint no existeixen tal qual. Així doncs, cal interpretar les teories de Bauman com el que representen, i no oblidar que l'anàlisi de la realitat és sempre més complex que les teories que se'n deriven.

En un pla més materialista, la modernitat líquida també genera reptes nous per a les disciplines territorials. Perquè si la modernitat líquida és sinònim d'individualisme i d'incertesa, el territori en pot sortir molt perjudicat, perquè aquest es construeix socialment $\mathrm{i}$ amb escales llargues de temps. És en aquest sentit que les polítiques espacials es troben amb una disjuntiva: o deixar-se portar pels fluxos de la modernitat líquida buscant la manera d'adaptar-s'hi, o enfrontar-se a la incertesa i a l'individualisme en benefici del que és permanent i social. Malauradament, la resolució d'aquesta disjuntiva queda molt lluny de l'abast d'aquest article.

\section{Agraïments}

Voldria donar sincers agraïments al Dr. Josep Pintó del LAGP de la UdG, per oferir-me la possibilitat d'entrar dins el seu grup de recerca i confiar en mi quan encara era un estudiant de llicenciatura. També a en Ramon Casadevall, per donar-me a conèixer l'obra de Zygmunt Bauman en les llargues converses dels dimarts a la tarda que han acabat inspirant aquest treball. Al professor Joan Nogué, també del LAGP, per les correccions i la seva predisposició i entrega com a tutor d'aquesta recerca. Als dos revisors anònims que amablement han fet precises aportacions a l'article, amb la qual cosa han ajudat a omplir els buits que hi havien quedat. I, finalment, a l'Astrid Ribot, pels seus comentaris i suggeriments i per la paciència que ha tingut aguantant les meves cavil.lacions sobre la modernitat líquida. 


\section{Referències bibliogràfiques}

Abad Aragón, L. (2010). «Gobernanza y desarrollo territorial: Una perspectiva geográfica». Gedeur, 10.

Albrechts, L. i Coppens, T. (2003). «Megacorridors: Striking a balance between the space of flows and the space of places». Journal of Transport Geography, 11 (3), 215-224. <http://dx.doi.org/10.1016/s0966-6923(03)00032-2>

Arenas, L. (2011). "Zygmunt Bauman: Paisajes de la modernidad líquida». Daimon, 54, 111-124.

Batty, M.; Hudson-Smith, A.; Milton, R. i Crooks, A. (2010). «Map mashups, Web 2.0 and the GIS revolution». Annals of GIS, 16 (1), 1-13. <http://dx.doi.org/10.1080/19475681003700831>

Bauman, Z. (1996). "From Pilgrim to Tourist». A: Hall, S. i Du Gay, P. (eds.). Questions of cultural identity. Londres: SAGE Publications.

- (2003a). Modernidad líquida. Mèxic: Fondo de Cultura Económica.

- (2003b). "Utopia with no topos». History of the Human Sciences, 16 (1), 11-25. <http://dx.doi.org/10.1177/0952695103016001003>

- (2006). Vida líquida. Barcelona: Paidós.

- (2010). Mundo-consumo: Ética del individuo en la aldea global. Barcelona: Paidós.

- (2012). «Times of interregnum». Ethics and Global Politics, 5 (1), 49-56. <http://dx.doi.org/10.3402/egp.v5i1.17200>

Beck, U. (1992). Risk society: Towards a new modernity. Londres: Sage.

Benach, N.; Albet i Mas, A. i Soja, E. W. (2010). Edward W. Soja: La perspectiva postmoderna de un geógrafo radical. Barcelona: Icaria.

Blatter, J. (2004). "From "spaces of place" to "spaces of flows"?: Territorial and functional governance in cross-border regions in Europe and North America». International Journal of Urban and Regional Research, 28 (3), 530-548. <http://dx.doi.org/10.1111/j.0309-1317.2004.00534.x>

BRIGHT, J. B. (2010). Liquid modernity as analytical framework: A study of isolated northern towns. Sheffield Hallam University. Tesi doctoral.

Caquard, S. (2013). "Cartography I: Mapping narrative cartography». Progress in Human Geography, 37 (1), 135-144. <http://dx.doi.org/10.1177/0309132511423796>

Castells, M. (1995). La ciudad informacional: Tecnologías de la información, reestructuración económica y el proceso urbano-regional. Madrid: Alianza.

- (2000). «The contours of the network society». Foresight, 2 (2), 151-157. <http://dx.doi.org/10.1108/14636680010802591>

Cools, M. (2010). Safety, societal problems and citizens' perceptions: New empirical data, theories, and analyses. Antwerpen: Maklu Uitgevers N.V.

Dematteis, G. i Governa, F. (2005). «Territorio y territorialidad en el desarrollo local: La contribución del modelo SLOT». Boletín de la AGE, 39, 31-58.

Ferrell, J. (2012). "Anarchy, Geography and Drift». Antipode, 44 (5), 16871704 . <http://dx.doi.org/10.1111/j.1467-8330.2012.01032.x>

García, A. G. i Bujalance, B. D. (2011). «From City to Metapolis: Making and Unmaking Landscapes in Andalusia». International Journal of Urban and Regional Research, 35 (6), 1272-1283.

<http://dx.doi.org/10.1111/j.1468-2427.2011.01104.x> 
González-Romero, D. (2010). «Turismo y ciudad: Espacio y lugar de imaginarios líquidos. Puerto Vallarta». Nodo, 5 (9), 5-18.

Graham, M. i Zook, M. (2011). «Visualizing global cyberscapes: Mapping user-generated placemarks». Journal of Urban Technology, 18 (1), 115-132. <http://dx.doi.org/10.1080/10630732.2011.578412>

Haklay, M.; Singleton, A. i Parker, C. (2008). «Web mapping 2.0: The neogeography of the GeoWeb». Geography Compass, 2 (6), 2011-2039. <http://dx.doi.org/10.1111/j.1749-8198.2008.00167.x>

Halfacree, K. (2012). «Heterolocal Identities?: Counter-Urbanisation, Second Homes, and Rural Consumption in the Era of Mobilities». Population, Space and Place, 18 (2), 209-224. <http://dx.doi.org/10.1002/psp.665>

Hallin, A. i Dobers, P. (2012). «Representation of space: Uncovering the political dimension of guided tours in Stockholm». Scandinavian Journal of Hospitality and Tourism, 12 (1), 8-26. <http://dx.doi.org/10.1080/15022250.2012.655079>

Harvey, D. (1998). La condición de la posmodernidad: Investigación sobre los orígenes del cambio cultural. Buenos Aires: Amorrortu.

Igoe, J.; Neves, K. i Brockington, D. (2010). "A spectacular eco-tour around the historic bloc: Theorising the convergence of biodiversity conservation and capitalist expansion". Antipode, 42 (3), 486-512. <http://dx.doi.org/10.1111/j.1467-8330.2010.00761.x>

Lefebvre, H. i Nicholson-Smith, D. (1991). The Production of Space. Oxford: Blackwell. Edició original: La production de l'espace. París: Anthropos, 1974.

Lyotard, J. (1979). La condition postmoderne: Rapport sur le savoir. París: Éditions de Minuit.

Mathiesen, T. (1997). «The viewer society: Michel Foucault's "Panopticon” revisited». Theoretical Criminology, 1 (2), 215-234. <http://dx.doi.org/10.1177/1362480697001002003>

Méndez, R.; Michelini, J. J. i Romeiro, P. (2006). "Redes socio-instucionales e innovación para el desarrollo de las ciudades intermedias». Ciudad y Territorio: Estudios Territoriales, 38 (148), 377-395.

Monnet, J. (2011). «The symbolism of place: A geography of relationships between space, power and identity». CyberGeo. <http://dx.doi.org/10.4000/cybergeo.24747>

Muñoz, F. (2008). Urbanalización: Paisajes comunes, lugares globales. Barcelona: Gustavo Gili.

Nogué, J. i Albet, A. (2007). "Cartografía de los cambios sociales y culturales». A: Romero, J. i Ortega Valcárcel, J. (eds.). Geografía humana: Procesos, riesgos e incertidumbres en un mundo globalizado. 2a ed. Barcelona: Ariel.

Nogué, J. i Vicente, J. (2004). «Landscape and national identity in Catalonia». Political Geography, 23 (2), 113-132.

<http://dx.doi.org/10.1016/j.polgeo.2003.09.005>

Phipps, A. (2011). «Comparisons of residents' perceptions of patterns and trends on computer-animated maps and graphs and on google maps of events in their neighbourhoods». Cartographica, 46 (3), 185-199. <http://dx.doi.org/10.3138/carto.46.3.185>

Piñon, F. (2013). «Mundo consume». 452 F, 8, 160-161. 
Pries, L. (2005). "Configurations of geographic and societal spaces: A sociological proposal between "methodological nationalism" and the spaces of flows». Global Networks, 5 (2), 167-190. <http://dx.doi.org/10.1111/j.1471-0374.2005.00113.x>

Puente Lozano, P. (2011). «La reconstrucción de los enfoques críticos contemporáneos y el rol del espacio». Documents d'Anàlisi Geogràfica, 57 (2), 223-254.

Quaglieri Domínguez, A. i Russo, A. P. (2010). «Paisajes urbanos en la época postturística: Propuesta de un marco analítico». Scripta Nova: Revista Electrónica de Geografía y Ciencias Sociales [en línia], 14 (323). <http://www.ub.es/geocrit/sn/sn-323.htm>.

Romero, J. i Ortega Valcárcel, J. (2007). Geografía humana: Procesos, riesgos e incertidumbres en un mundo globalizado. 2a ed. Barcelona: Ariel.

SÁnchez, C. (2006). «Flujos, elementos y formas sociales: La modernidad líquida a debate». Politica y Sociedad, 43 (2), 63-84.

Santos, M. (1995). "El retorno del territorio». A: Bosque, J. i Ortega, F. (eds.). Comentario de textos geográficos: Historia y crítica del pensamiento geográfico. Barcelona: Oikos-Tau, 166-170.

Soja, E. W. (1990). Postmodern geographies: The reassertion of space in critical social theory. Londres: Verso.

- (1996). Thirdspace: Journeys to Los Angeles and other real-and-imagined places. Malden: Blackwell.

- (2000). Postmetropolis: Critical studies of cities and regions. Oxford: Blackwell. 